\title{
ОРГАНИЗАЦИОННО-ПЕДАГОГИЧЕСКИЕ УСЛОВИЯ ДИСТАНЦИОННЫХ ТЕХНОЛОГИЙ ОБУЧЕНИЯ СО СТУДЕНТАМИ НАПРАВЛЕНИЙ ПОДГОТОВКИ «ФИЗИЧЕСКАЯ КУЛЬТУРА»
}

\section{ORGANIZATIONAL AND PEDAGOGICAL CONDITIONS OF DISTANCE LEARNING TECHNOLOGIES WITH STUDENTS OF THE AREAS OF TRAINING "PHYSICAL CULTURE"}

\section{E. Sukhanova \\ O. Antipov \\ R. Gezha}

Summary: The article is dedicated to the substantiation of the need for organizational and pedagogical conditions of distance learning technologies with students of the training direction "Physical Culture". The author outlines the methodological foundations, main approaches, tasks and methodology of the organizational and pedagogical conditions of distance learning technologies. The educational activity of students of the Department of Physical Education and Sports is closely related to the repeated skipping of lectures and practical classes at universities, due to the busy training schedule, frequent trips to training camps, competitions. For such students, a special form of education is needed, which would not be inferior in effectiveness to the traditional tools of educational activity adopted at universities. The article touches upon one of the urgent problems of modern education - the organization of distance learning with future specialists in physical education and sports. The author considers the development and current state of distance education in universities in the process of professional training of students in the direction of "Physical culture".

The conditions for the organization of the educational process using remote technology Moodle (and other similar platforms) are defined. The main advantages of distance learning for students and teachers are identified, as well as the possibility of integrating traditional and distance learning, which gives rise to a new form of learning - mixed. The negative aspects of using the Moodle system for effective professional training of future specialists of this orientation are presented.

Keywords: distance learning, distance education, physical culture and sports, Moodle platform, positive and negative impact of distance learning.
Суханова Елена Юрьевна

к.б.н., доцент, ФГБОУ ВО «Московская государственная академия ветеринарной медицины и биотехнологии имени К.И. Скрябина»

lena.suxanova@yandex.ru

Антипов Олег Владимирович

к.б.н., дочент, ФГБОУ ВО «Московская государственная академия ветеринарной медицины и биотехнологии имени К.И. Скрябина» antipov_ov@bk.ru

Гежа Роман Валерьевич преподаватель, ФГБОУ ВО «Московская государственная академия ветеринарной медицины и биотехнологии имени К.И. Скрябина» gezha.r@yandex.ru

Аннотация: Статья посвящается обоснованию необходимости организационно-педагогических условий дистанционных технологий обучения со студентами направления подготовки «Физическая культура». Авторами обозначены методологические основы, основные подходы, задачи и методика проведения организационно-педагогических условий дистанционных технологий обучения. Учебная деятельность студентов кафедры физического воспитания и спорта тесно связана с многократными пропусками лекционных и практических занятий в вузах, вследствие напряженного графика тренировок, частыми выездами на учебно-тренировочные сборы, соревнования. Для таких студентов нужна особая форма обучения, которая не уступала бы по эффективности традиционным инструментам учебной деятельности, принятой в университетах. В статье затрагивается одна из актуальных проблем современного образования - организации дистанционного обучения с будущими специалистами по физическому воспитанию и спорту. Авторами рассмотрено развитие и современное состояние дистанционного образования в вузах в процессе профессиональной подготовки студентов по направлению «Физическая культура».

Определены условия организации учебного процесса с использованием дистанционной технологии Moodle (и прочих аналогичных платформ). Определении главные преимущества обучения по дистанционной форме для студентов, преподавателей, а также возможности интеграции традиционного и дистанционного обучения, что порождает новую форму обучения - смешанную. Представлены негативные аспекты использования системы Moodle для осуществления эффективной профессиональной подготовки будущих специалистов указанной направленности.

Ключевые слова: дистанционное обучение, дистанционное образование, физическая культура и спорт, платформа Moodle, положительное и отрицательное влияние дистанционного обучения. сходя из отечественных нормативных документов, дистанционное образование это «возможность учиться и получать необходимые знания удален- но от учебного заведения в любое удобное время» [8]. Электронное образование, получает активное распространение не только в научно-методической литературе, 
но и среди всех слоев населения благодаря имеющейся информационной инфраструктуре, «совокупности различных информационных систем, информационных ресурсов, телекоммуникационных сетей, средств коммуникаций и управления информационными потоками, а также организационно-технических структур, механизмов, обеспечивающих их функционирование» [1].

На сегодняшний день, в условиях карантина или режима самоизоляции в пандемию Covid-19, подготовка будущих тренеров, преподавателей, специалистов по физическому воспитанию и спорту происходит в сложных социально-экономических условиях [12]. Такая тенденция требует реформирования образования в высших учебных заведениях: изменения классической формы обучение на дистанционную, параллельно внедряя концепцию дистанционного образования, которая предполагает разработку различных технологий, в том числе технологии смешанного обучения. Они дадут возможность повысить и усовершенствовать эффективность образовательного процесса.

В середине XX века основными формами в процессе подготовки будущих учителей были лекции, тематические спецкурсы и спец. семинары, факультативные курсы, семинарские, практические и лабораторные занятия. В дальнейшем (80-90-е годы XX в.) к методам обучения вводятся научно-методические и читательские конференции, педагогические тренинги, беседы, диспуты или дискуссии, деловые и ролевые игры, викторины, ситуационные и познавательные задачи, выполнение курсовых работ с включением экспериментальных исследований, дипломных работ и некоторые другие. Авторы отмечают, что каждая форма играла существенную роль в подготовке будущих учителей физической культуры. Так, например, проблемные лекции, познавательные и ситуационные задачи с широкой демонстрацией схем, таблиц, диаграмм, рисунков, учебных диафильмов соревнований, спортивных праздников, спартакиад направлены не только на усвоение студентами научных знаний, но и на развитие педагогического мышления, повышению познавательной активности студентов, пробуждения у них интереса к самостоятельной работе в школе. Целью семинарских занятий является самостоятельная подготовка студентом информационно насыщенного, эмоционального, убедительного доклада по области физической культуры с последующей апробацией в группе, на заседании педагогического совета школы, родительских собраниях и тому подобное.

Педагогически целесообразными задачами для семинарских занятий является и составление будущими преподавателями физической культуры учебных программ для изучения упражнений по различным видам спорта; комплексов физических упражнений для всех форм физкультурно-оздоровительных мероприятий (физкультпауз, физкультминут, гимнастических упражнений к занятиям, динамических перерывов, микропауз). Также были внедрены нетрадиционные формы подготовки студентов, например, педагогический тренинг, предназначенный для моделирования сложных реальных ситуаций, которые могли возникнуть во время организации физкультурно-оздоровительной и спортивно-массовой работы во внеурочное время.

Отмечаем, что автор, определяет перспективные направления в подготовке будущих учителей. Так, одним из таких путей является распространение в практической педагогической подготовке студентов факультетов физического воспитания, в том числе интерактивных форм обучения на различных учебных платформах.

Среди новейших трендов развития высших учебных заведений перспективным созданием совершенствование профессионального образования является реализация новых педагогических технологий и принципов организации учебного процесса, реализация новых моделей и содержания непрерывного обучения, в том числе дистанционного обучения, основанное на широком использовании современных информационных и коммуникационных технологий (ИКТ) [7].

Технологии дистанционного обучения позволяют осуществлять обучение на расстоянии, при этом проверяя качество усвоенных студентом знаний, используя активные методы обучения. Также, главным преимуществом дистанционного обучения исследователи считают гибкость, модульность, технологичность, обновление роли учителя, повышение мотивации к самоорганизации студентов, при этом обучение становится более интерактивным, самостоятельным.

Целесообразность введения дистанционного обучения является предметом исследования как отечественных, так и зарубежных специалистов по физическому воспитанию и спорту. В научной публикации С. Барбуту и А. Кэкка определено, что дистанционное обучение студентов дешевле стационарного, в условиях недофинансирования учреждений высшего образование является более целесообразным, и в будущем может приобрести полноценное внедрение [4].

Х. Бекьюв и др. в своей статье определили особенности смешанной формы дистанционного обучения для студентов специальности «Физическое воспитание и спорт», использование интерактивных технологий, методов и средств дистанционного обучения [5].

Общие вопросы организационно-педагогических условий внедрения дистанционных технологий обучения со студентами специальности физическая культура и спорт представляют научно-практические исследования обозначенных вопросов такие издания, как «Информационные технологии и средства обучения» [10], «Научно-методические основы использования инфор- 
мационных технологий в области физической культуры и спорта» [2].

В документации вузов о системе образования, дистанционная форма обучения приравнивается ко второй основной форме обучения в мировых ведущих вузов [8]. Но, на сегодняшний день существуют определенные вопросы по использование дистанционных технологий обучения в процессе подготовки будущих специалистов в области физической культуры и спорта.

Следует также отметить, что будущие специалисты в области физического воспитания и спорта вследствие напряженного графика тренировок, частыми выездами на учебно-тренировочные сборы, соревнования, не в полной мере могут посещать академические занятия. Поэтому для таких студентов нужна особая форма обучения, которая не уступала бы по эффективности традиционной учебной деятельности, принятой в учреждениях высшего образования, одной из таких форм является дистанционное обучение.

В учреждениях высшего образования организация дистанционного обучения при подготовке специалистов в сфере физического воспитания и спорта позволяет систематически проводить обучение студентов вне учебного заведения, во время карантина, учебных тренировок, сборов, соревнований, развивать новые формы самостоятельного образования. Однако, внедрение технологии дистанционного обучения в образовательный процесс, по нашему мнению, еще не приобрело должного развития, а преподаватель и студент сталкивается с разного рода проблемами (качество интернет-связи, непонятность исполнения двигательных умений, отсутствие живого общения, контакта студента и преподавателя, большая трудоемкость и необходимость значительных материальных и временных расходов во время разработки дистанционных курсов, и т.п.).

Мы считаем, что главной проблемой во время введения дистанционного обучения у студентов физической направленности является невозможность усвоения учебного материала в полной мере, вследствие специфичности предметной области общепрофессиональных и спортивных дисциплин.

Цель исследования заключается в изучении особенностей применения и внедрения в учебно-воспитательный процесс дистанционного обучения со студентами направления подготовки «Физическая культура» во время преподавания спортивно-педагогических дисциплин.

Становление и развитие дистанционного обучения получили всестороннее освещение в научных исследованиях отечественных и зарубежных специалистов [6].

Дистанционное обучение представляет собой при- обретение знаний студентом через всемирную сеть Интернет и другие компьютерные коммуникационные каналы, что обеспечивает интенсивный и тесный двусторонний обмен информацией между слушателями и преподавателем.

Сейчас в системе физического воспитания студентов в вузах сложилась проблемная ситуация, как проводить практические занятия во время проведения дистанционного обучения, что требует немедленного решения.

Одно из таких решений возможно при условии использования качественной дистанционной платформы и построения индивидуальной, систематической работы со студентом для усвоения необходимого учебного материала, привлечение действенных методов и форм обучения в том числе информационных и коммуникационных технологий.

В учебно-воспитательном процессе во время дистанционной формы обучения, преподаватели кафедры физического воспитания и спорта (вуз «Х», г. Москва) активно используют систему Moodle (в рамках данного исследования важно отметить, что дистанционное обучение на аналогичных образовательных платформах устроены по единому принципу), которая предназначена для организации и управления обучением в сетевой среде с использованием ИКТ. Она надежна в эксплуатации, является простой в использовании и администрировании, обеспечивает безопасность информации и ее передачу от преподавателя к студенту, осуществляет оценивание учебных достижений студентов.

Система спроектирована в соответствии с реализацией методов коллективной деятельности субъектов обучения и ориентирована прежде всего на организацию взаимодействия между преподавателем и учениками, хотя подходит и для организации традиционных дистанционных курсов, а также поддержки очного обучения.

Доступный интерфейс не требует специальных навыков по созданию электронных учебно-методических материалов. Основными средствами, что позволяют субъектам обучения общаться между собой, являются: форум - средство offline общения, общий для всех студентов, размещенный на главной странице платформы; электронная почта; обмен вложенными файлами с преподавателем; чат-средство online общение между преподавателями и студентами; обмен личными сообщениями [9].

Для кафедры физического воспитания и спорта, которая обеспечивает подготовку специалистов по конкретному виду спорта, преподаватели работают со студентами преимущественно в режиме персонального сотрудничества с обеспечением дистанционной составляющей учебных дисциплин [8]. Учебная дисциплина размещена на платформе Moodle, и имеет стандартные 
компоненты: учебно-методический материал включает в себя рабочую учебную программу про курс, силабус; в теоретической части курса содержатся лекционные материалы, дополнительные мультимедийные учебнометодические материалы; в практической части - практические задания по теме изученных лекций, отдельные ресурсы для каждого занятия; перечень рекомендуемой учебной литературы; тестовая контрольная работа включает в себя тестовые задания по каждой теме лекций для начисления баллов студенту, задания для самостоятельной работы (список тем для написания реферата, индивидуально-опытного задания, методические рекомендации и т. п), итоговая аттестация (экзаменационная или зачетная работа).

Для дисциплин типа «Теория и методика преподавания спортивных игр (волейбол, баскетбол и т.п.)», «Теория и методика преподавания спортивных игр (гимнастика и прочее)», «Силовые виды спорта», где практические занятия проходят в спортивных комплексах, целесообразным является размещение информации сугубо ознакомительного характера с дополнительным уточнениями в виде сопровождающих видеоматериалов (например, фрагменты тренировок и соревнований, обучающие видео-курсы тренировки, комментарии специалистов, видео-отчеты и т.п.). Понятно, что тестовые задания являются недостаточно корректными в качества итогового контроля, даже если будут сопровождаться видеоотчетом. Следует также отметить, что не все учреждения высшего образования размещают дистанционные курсы для студентов специальностей «Физическая культура».

Не смотря на явные преимущества в дистанционном обучении, специфика профессиональной подготовки будущего специалиста по физической культуре и спорта накладывает ряд ограничений на использование дистанционных технологий: виртуальных стадионов и спортивных залов пока не создали, усвоение техники движений, методика обучения, сдачи спортивных нормативов, проведение контрольных игр подобное не всегда вписывается в систему дистанционного образования.

Главными недостатками дистанционного обучение является:

- отсутствие живого общения, контакта студента и преподавателя;

- большая трудоемкость и необходимость значительных материальных затрат при разработке дистанционных курсов;

- необходимость формирования дополнительной мотивации и самостоятельности у студентов;

- высокая зависимость от качества работы сети Интернет и технической поддержки систем;

- не полное усвоение учебного материала: практических умений и навыков по обучению техники основных элементов из выбранного вида спорта;

- невозможность проведения учебного занятие студентом, формулирующим неуверенность во время проведения и ошибки в технике воспитанников.

Реалии настоящего таковы, что будущее все же за смешанной формой обучения, где наряду с дистанционными формами должны присутствовать и формы практических занятий, поскольку одним из важнейших факторов, влияющих на успех обучения студентов, есть преподаватель. Невозможно в полной мере овладеть рациональной техникой движений на расстоянии, даже используя самые современные спортивные приборы и компьютеризированные тренажеры, видеофильмы и видеоролики с изображением образцового выполнения техники движений. Безусловно, новая мультимедийная образовательная среда является большим помощником в обучении, однако лишь опытный преподаватель (тренер) может научить рациональным двигательным и тактическим действиям, раскрыть индивидуальность студента и поставить идеальную технику движений [3].

Таким образом, современный уровень развития информационных технологий позволяет эффективно и качественно вводить относительно новую форму обучение - смешанное и дистанционное обучение [11]. Использование платформы Moodle (любой образовательной платформы) позволяет формировать профессиональные компетенции у студентов как практического, так и теоретического характера, овладение большой базой теоретических знаний, формирование способностей к самообучению и самоконтролю, самоподготовке и самоадаптация к будущей профессиональной деятельности в условиях социально-экономических преобразований современного общества.

Следует также отметить, что внедрение дистанционного обучения при преподавании спортивно-педагогических дисциплин должно происходить в двух направлениях: при усвоении теоретического раздела учебной программы по дисциплине с использованием, как традиционных средств, так и средств ИКТ. Во время усвоения практического раздела, целесообразно использовать видео-тренировок, уроков, обучения техническим элементам и двигательным навыкам.

Однако, в подготовке студентов направления подготовки «Физическая культура» и стоит отметить, что любая платформа дистанционного обучения не в состоянии в полной мере обеспечить студентам, спортсменам, реальные условия тренировки и спортивно-педагогического совершенствования в спортивных и специализированных залах, на игровых и соревновательных площадках, стадионах, бассейне, а также усвоение методику обучение различным двигательным умениям. Поэтому традиционный компонент подготовки остается ведущим при подготовке будущих специалистов по физическому воспитания и спорта. 


\section{ЛИТЕРАТУРА}

1. Алеева Ю.В., Попова Н.В. Развитие познавательной активности студентов вуза в процессе проблемного обучения // Экономика. Профессия. Бизнес. 2015. T.1. №1(1). C. 58-60.

2. Попова Н.В., Баринова Н.Г. Интегративная модель формирования профессиональной направленности бакалавров в процессе компетентностно-ориентированного образования // European Social Science Journal. 2017. №11. C. 405-413.

3. Попова Н.В., Баянкина Д.Е. Инновационные педагогические технологии как условие формирования профессиональной компетенции бакалавров института физической культуры и спорта. // Мир науки, культуры, образования. 2017. Т. 63. №2. С. 194-198.

4. Barbutiu S.M., Kack A. Integrating digital literacy in teacher education - the perpetual challenge of a learning organization // Edulearn16: 8th international conference on education and new learning technologies. 2016. P. 4255- 4264. D0l: 10.21125/edulearn.2016.2029.

5. Becuwe H., Roblin N.P., Tonduer J., Thys J., Castelein E., Voogt J. Conditions for the successful implempetion of teacher educator design teams for ICT integration: A Delphi study // Australasian Journal of Educational Technology. 2017. Vol. 33, is. 2. P. 159-172. D0I: 10.14742/ ajet.2789.

6. Cober R., Tan E., Slotta J., So H.J., Konings H.D. Teachers as participatory designers: two case studies with technology-enhanced learning environments // Australasian Journal of Educational Technology. 2015. Vol. 43, is. 2. P. 203-228. D0l: 10.1007/s11251-014-9339-0.

7. Беликов В.А. Дидактика практикоориентированного образования: моногр. / В.А. Беликов, П.Ю. Романов, А.С. Валеев. М.: ИНФРА-М, 2018.267 с.

8. Сайгушев Н.Я. Уровни рефлексивного управления профессиональным становлением будущего учителя изобразительного искусства / Н.Я. Сайгушев, 0.А. Веденеева, Ю.Б. Мелехова // Искусство и образование. 2018. №4. С. 137-151.

9. Ахтамова С.С., Чернышов В. Н. Электронное обучение в педагогическом вузе: плюсы и минусы // Человек и язык в коммуникативном пространстве: сборник научных статей. 2018. Т. 9, №9. С. 193-199.

10. Суханова Н.Т. Электронное обучение в вузе: оценка качества электронных ресурсов // Проблемы современного педагогического образования. 2016. №52-6. С. 302.

11. Татаринов К.А. Мобильное обучение поколения «Z» // Балтийский гуманитарный журнал. 2019. №2. С. 103.

12. Титов А.А. Дистанционное обучение в условиях самоизоляции // Актуальные научные исследования в современном мире. 2020. № 5-2. - С. 129.

( С Суханова Елена Юрьевна (lena.suхanova@yandex.ru), Антипов Олег Владимирович (antipov_ov@bk.ru), Гежа Роман Валерьевич (gezha.r@yandex.ru).

Журнал «Современная наука: актуальные проблемы теории и практики»

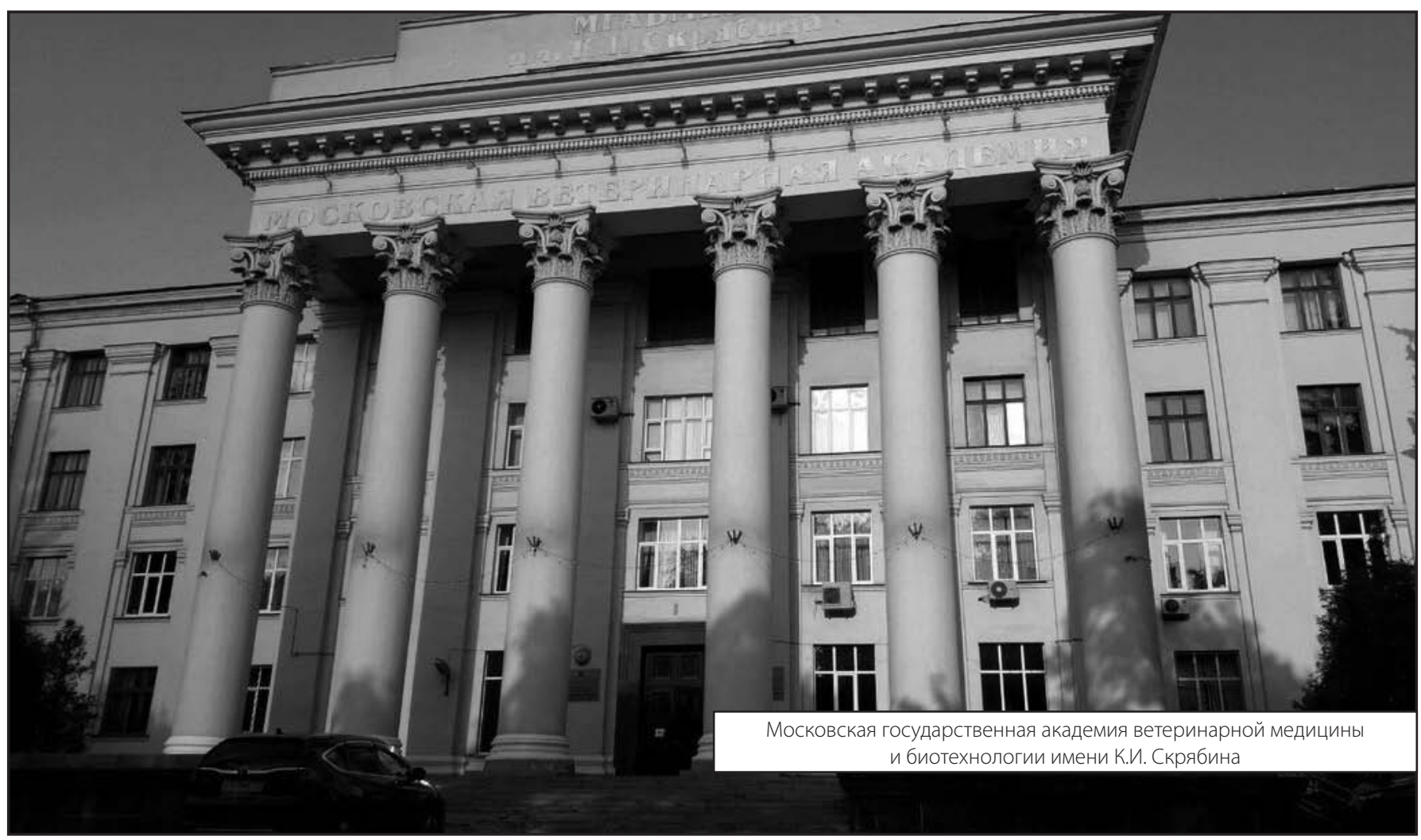

